\title{
OBTENÇÃO DE EXTRATOS DA POLPA DE AÇAÍ (EUTERPE OLERACEA) LIOFILIZADA POR EXTRAÇÃO SUPERCRÍTICA: ISOTERMAS DE RENDIMENTO GLOBAL E COMPOSIÇÃO EM ÁCIDOS GRAXOS
}

C. C. R. BATISTA ${ }^{1}$, A. P. M. SANTOS 2 , A. P. S. SILVA ${ }^{3}$, R. M. CORDEIRO ${ }^{4}$, M. E. ARAÚJO $^{5}$, N. T. MACHADO ${ }^{5}$, A. M. C. RODRIGUES ${ }^{6}$, R. N. CARVALHO JR ${ }^{6}$.

${ }^{1}$ Universidade Federal do Pará, Programa em Engenharia dos Recursos Naturais da Amazônia, Curso de Doutorado em Engenharia de Recursos Naturais ${ }^{1}$

${ }^{2}$ Universidade Federal do Pará, Faculdade de Engenharia de Alimentos, Curso de Engenharia de Alimentos

${ }^{3}$ Universidade Federal do Pará, Faculdade de Ciências Exatas e Tecnologia, Curso de Engenharia Industrial

${ }^{4}$ Universidade Federal do Pará, Programa de Pós Graduação em Engenharia Química, Curso de Mestrado

${ }^{5}$ Universidade Federal do Pará, Faculdade de Engenharia Química

${ }^{6}$ Universidade Federal do Pará, Faculdade de Alimentos

Email para contato: camila_cassia05@yahoo.com.br

\begin{abstract}
RESUMO - O trabalho tem como objetivo realizar uma avaliação sistemática da influência das variáveis do processo (temperatura, pressão e densidade de solvente) no rendimento global e composição em ácidos graxos de extratos obtidos da polpa de açaí (Euterpe olearacea) liofilizada na extração com dióxido de carbono supercrítico. Avaliaram-se três isotérmicas de rendimento global nas temperaturas de 50,60 e $70^{\circ} \mathrm{C}$ combinadas com densidades de $\mathrm{CO}_{2}$ de $0.7,0.8,0.9$ $\mathrm{g} / \mathrm{ml}$, e com pressões variando de 150 a 490 bar, e vazão volumétrica de $\mathrm{CO}_{2}$ de $3 \mathrm{~L} / \mathrm{min}$. O tempo de extração foi de 0,5 horas de período estático e 3 horas de período dinâmico. A composição em ácidos graxos para cada extrato foi determinada por conversão de ácidos graxos em ésteres metílicos, baseado pelo método proposto por Rodrigues et al. (2010). Observou-se que maiores rendimentos foram obtidos na temperatura de $70^{\circ} \mathrm{C}$ e pressão de 490 bar e menores rendimentos na temperatura de $60^{\circ} \mathrm{C}$ e pressão de 190 bar.
\end{abstract}

\section{INTRODUÇÃO}

O desenvolvimento de tecnologias e processos de produção de extratos naturais livres de compostos químicos tóxicos é favorecido por diversas questões, entre elas, o interesse industrial na obtenção de substâncias bioativas de alto valor agregado e a crescente restrição à utilização de substâncias sintéticas. E umas das alternativas tecnológicas de obtenção de extratos é o processo de extração com fluido supercrítico (EFSC), em especial, com o dióxido de carbono, o qual proporciona a obtenção de produtos isentos de solventes residuais, possuindo os produtos obtidos qualidade superiores, quando comparadas aos produtos obtidos por técnicas convencionais. 
A extração por fluido supercrítico é um método de separação que, até certo ponto, une os princípios da destilação e extração por solvente, utilizando as propriedades especiais de fluidos nas condições supercríticas (WENNERSTEN, 1992). Trata-se de um processo promissor para extrair compostos naturais de matérias-primas vegetais, evitando a degradação térmica e a presença de resíduos de solventes nos extratos (GARCÍA-RISCO et al., 2011). Além disso, apresenta várias vantagens em relação às técnicas de extração convencionais. A temperatura de operação no EFSC é razoavelmente baixa, permitindo que compostos termicamente estáveis sejam separados. Diferentemente do que ocorre nas técnicas tradicionais, no processo EFSC a extração acontece de forma quase instantânea, com extratos sendo separados dos solventes apenas por redução na pressão do sistema ou ajuste da temperatura (BHATTACHARJEE et al., 2007).

Os fluidos supercríticos apresentam viscosidade baixa como a de um gás, alta densidade como os líquidos e difusão intermediária entre gases e líquidos, variando com a sua densidade. São prontamente adaptáveis a muitas separações difíceis, não somente por permitir a separação de materiais instáveis termicamente, a baixas temperaturas, mas também devido a alta compressibilidade e solubilidade exponencial, e ainda efetuar separações com pequenas variações de pressão (SILVA et al., 1997). Entre diversos compostos utilizados nas EFSC, o dióxido de carbono é o mais comumente utilizado, pois reúne as condições ideais de solvente: inerte, atóxico, gasoso em condições normais, de baixo custo, podendo ser facilmente separado do produto extraído e recuperado no processo.

Neste contexto, o trabalho tem como objetivo realizar uma avaliação sistemática da influência das variáveis do processo (temperatura, pressão e densidade de solvente) no rendimento global e composição em ácidos graxos de extratos obtidos da polpa de açaí (Euterpe olearacea) liofilizada a partir da extração com dióxido de carbono supercrítico, afim de que possa colaborar com estudos futuros de obtenção de extrato usando a tecnologia do fluido supercrítico para fins alimentícios, cosméticos e farmacêuticos.

\section{MATERIAIS E MÉTODOS}

\subsection{Matéria-prima}

Os frutos de açaí foram adquiridos na Feira do Município de Abaetetuba, no estado do Pará, durante o período de safra em agosto de 2013.

\subsection{Caracterização e preparação da matéria-prima}

Despolpamento: Os frutos de açaí foram lavados com água corrente e colocados em tanques com água quente a $50^{\circ} \mathrm{C}$ para o amolecimento da polpa durante 15 minutos. Depois, os frutos foram colocados na batedeira de açaí e adicionou-se água filtrada para retirada da polpa. A polpa obtida foi armazenada em sacos plásticos e congelada em freezer.

Liofilização: Inicialmente a polpa de açaí foi triturada em liquidificador (BRITÂNICA), acondicionada nas bandejas do liofilizador e levadas em freezer vertical (BRASTEMP) para 
congelamento na temperatura de $-25^{\circ} \mathrm{C}$ durante 24 horas. Em seguida a polpa congelada junto às bandejas foi colocada no liofilizador (LIOTOP, modelo: L101) e submetidas a condições de liofilização a uma pressão de $138 \mu \mathrm{mmHg}$ e temperatura do condensador de $-51^{\circ} \mathrm{C}$ durante 24 horas. A polpa de açaí liofilizada foi armazenada em sacos plásticos a vácuo e levados ao freezer.

Determinação da granulometria: A polpa de açaí liofilizada foi introduzida num jogo de peneiras de série padrão Tyler 8 a 42 meshes. A distribuição granulométrica foi realizada através de um agitador de peneiras tipo magnético (BERTEL, $\mathrm{N}^{\circ} 1713$ ) durante 30 minutos. A quantidade de massa retida em cada peneira foi pesada em balança semi-analítica (QUIMIS, Q520), acondicionada em sacos plásticos e armazenada em freezer doméstico (ELETROLUX). O diâmetro médio das partículas foi determinado de acordo com o método da ASAE (1998).

Determinação da umidade: $O$ teor de umidade da polpa de açaí foi determinado utilizando um analisador de umidade por Infra-Vermelho (GEHAKA, Modelo IV 2500).

Determinação da densidade real das partículas: A densidade real foi determinada pela Central analítica do Instituto de Química da UNICAMP, utilizando um picnômetro de gás hélio conforme manual de operação de equipamento (Picnômetro automático Quantachrome Ultrapyc 12200e).

\subsection{Unidade de extração supercrítica}

Para obtenção dos extratos da polpa de açaí liofilizada foi utilizado a unidade Spe- ed SFE (Applied Separations, Inc., Allentown, PA USA, modelo 7071) equipada com recirculador (POLYSCIENCE, F08400796), um compressor (SCHULZ, modelo CSA 7,8), um medidor de vazão de $\mathrm{CO}_{2}$ na saída do sistema ( Alicat Scientific, M5SLPM) e um cilindro de $\mathrm{CO}_{2}$ (LINDE, pureza 99,9\% ).

\subsection{Determinação das isotermas de rendimento global}

Os experimentos para a determinação das isotermas de rendimento global foram realizados na célula de extração com $1,4 \mathrm{~cm}$ de diâmetro e $32,5 \mathrm{~cm}$ de altura. Foram realizadas extrações em três temperaturas $\left(50,60\right.$ e $\left.70^{\circ} \mathrm{C}\right)$ combinadas com densidade de $\mathrm{CO}_{2}$ $(0.7,0.8$ e $0.9 \mathrm{~g} / \mathrm{ml})$ em pressões que variaram de 150 a 490 bar totalizando nove ensaios que foram replicados. O tempo de processo de extração ( 0.5 horas de período estático e 3 horas de período dinâmico), a massa de matéria-prima alimentada (10 gramas) na célula e a vazão de $\mathrm{CO}_{2}(3 \mathrm{~L} / \mathrm{min})$ foram mantidos constantes.

\subsection{Composição em ácidos graxos}

A composição em ácidos graxos dos extratos obtidos da polpa de açaí liofilizada foi determinada pela conversão em ésteres metílicos de ácidos graxos (EMAGs) de acordo com o método proposto por Rodrigues et al. (2010), utilizando para análise um Cromatógrafo a Gás (Varian modelo CP 3380) acoplado com detector de ionização em chama (DIC) e coluna 
capilar CPSil 88 de $60 \mathrm{~m}$ de comprimento, diâmetro interno de $0.25 \mathrm{~mm}$ e espessura do filme de $0.25 \mu \mathrm{m}$ da Varian Inc. Foi injetado $1 \mu$, sendo que gás hélio foi utilizado como fase móvel com vazão de $0,9 \mathrm{ml} / \mathrm{min}$ e o DIC e o injetor (splitratio $1: 100$ ) a $250{ }^{\circ} \mathrm{C}$. A programação de temperatura da coluna foi desempenhada de $80{ }^{\circ} \mathrm{C}$ por 4 min e então elevada para $205^{\circ} \mathrm{C} \operatorname{com} 4{ }^{\circ} \mathrm{C} / \mathrm{min}$.

A identificação dos picos individuais de ácidos graxos foi realizada com base em padrões (Nu-check-prep Inc, EUA). Assim como, utilizou-se o software Varian Star 3.4.1 para calcular os tempos de retenção e áreas dos picos. Os resultados foram expressos com percentuais relativos de ácidos graxos totais.

\section{RESULTADOS E DISCUSSÕES}

A polpa de açaí liofilizada apresentou $2.3 \pm 0.2 \%$ de umidade, densidade real $\left(\rho_{\mathrm{r}}\right)$ de $1.23 \pm 0.01 \mathrm{~g} / \mathrm{cm}^{3}$. O diâmetro médio das partículas foi de $0.8659 \mathrm{~mm}$.

No gráfico1, estão apresentados os resultados obtidos experimentalmente das Isotermas de rendimentos globais em base seca para as temperaturas de 50,60 e $70^{\circ} \mathrm{C}$, com seus respectivos desvios pontuais. Pode-se observar que o maior rendimento foi obtido na condição experimental de $70{ }^{\circ} \mathrm{C}$ e 490 bar, enquanto que o menor rendimento foi obtido na

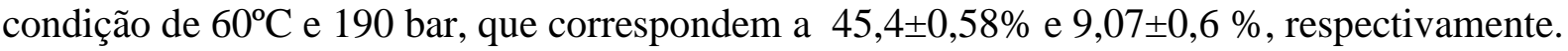
$\mathrm{O}$ efeito da temperatura e pressão influência diretamente na densidade e, consequentemente, no poder de solubilização do solvente. A isoterma de $70^{\circ} \mathrm{C}$ foi a que apresentou maior rendimento para todas as pressões aplicadas enquanto a isoterma de $60^{\circ} \mathrm{C}$ foi a que apresentou menor rendimento. Com o aumento na densidade do dióxido de carbono houve o aumento no rendimento global de extrato em todas as condições experimentais estudadas com isso observa-se que o efeito da densidade do dióxido de carbono foi a que mais prevaleceu.

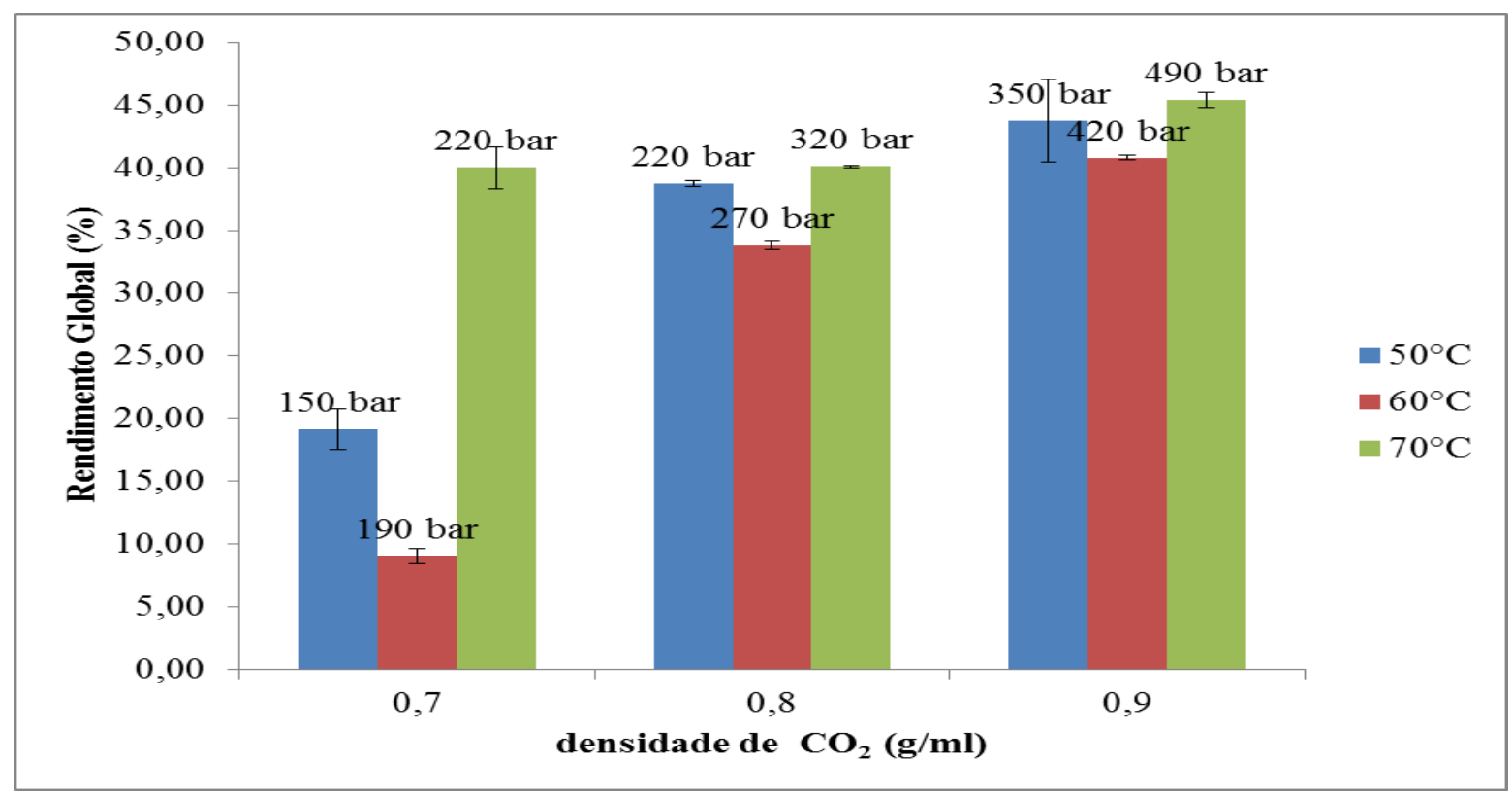

Gráfico1-Isotermas de rendimento mássico global 


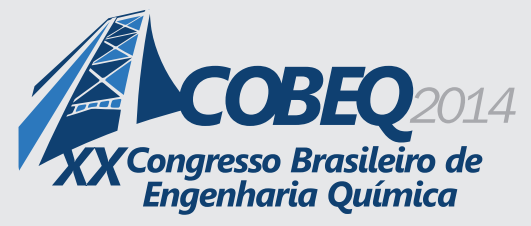

Na tabela 1, estão apresentados o perfil de ácidos graxos dos extratos de polpa de açaí liofilizada obtidos através de extração com dióxido de carbono no estado supercrítico em diferentes condições operacionais. O desvio padrão para todos os ácidos graxos foi menor que 1.8\%. A quantidade total de ácidos graxos nos extratos de açaí variou de 0.02 a $65.81 \%$. Foi observado a presença de ácido caprílico (C8:0) em todas as condições experimentais utilizadas para obter o extrato de açaí. A condição 320 bar $/ 70^{\circ} \mathrm{C}$ apresentou maior concentração de ácido caprílico enquanto a menor concentração foi encontrada na condição de $490 \mathrm{bar} / 70^{\circ} \mathrm{C}$. Traços de ácido cáprico (C10:0) foi obtido nas condições de $150 \mathrm{bar} / 50^{\circ} \mathrm{C}, 220 \mathrm{bar} / 70^{\circ} \mathrm{C}, 320 \mathrm{bar} / 70^{\circ} \mathrm{C}$ e 490 bar $/ 70^{\circ} \mathrm{C}$. Para o ácido tridecanoico $(\mathrm{C} 13: 0)$, ácido pentadecanoíco $(\mathrm{C} 15: 0)$ e ácido linolênico (C18:3) apenas traços foram encontrados em todas as condições experimentais. O principal ácido graxo saturado (SFA) em todas as condições de extração foi o ácido palmítico (C16:0) com concentração de $90.86 \%$ na condição de 320 bar $/ 70^{\circ} \mathrm{C}$ seguido pelo ácido esteárico (C18:0). Em relação aos ácidos graxos poli-insaturados (PUFA), o ácido oleico (C18:1) apresentou maior concentração $65.81 \%$ seguido pelo linoleico (C18:2) e o ácido palmitoleico (C16:1). Analises do perfil de ácidos graxos de extrato de açaí indica uma razão de saturado/insaturado baixo e a quantidade de MUFA é maior que a de PUFA. Os resultados encontrados neste trabalho para o ácido oleico são próximos aos encontrados por Nascimento et al., (2008), Schauss et al., (2006) e Rogez, (2000) de 52\%, 56.2\% e 54.9\%, respectivamente, com exceção do extrato obtido nas condições de $320 \mathrm{bar} / 70^{\circ} \mathrm{C}$, no qual o percentual desse ácido foi de $0.23 \%$, sendo que nessas condições operacionais observou-se maior seletividade para obtenção de ácido palmítico 90.86\%).

Tabela 1- Composição em ácidos graxos de extrato de açaí

\begin{tabular}{|c|c|c|c|c|c|c|c|c|c|}
\hline \multicolumn{10}{|c|}{ Concentração de Ácidos Graxos em \% g/100mg } \\
\hline $\begin{array}{l}\text { Ácidos } \\
\text { Graxos }\end{array}$ & $\begin{array}{l}50^{\circ} \mathrm{C}, \\
150 \text { bar } \\
\end{array}$ & $\begin{array}{l}50^{\circ} \mathrm{C}, \\
220 \text { bar }\end{array}$ & $\begin{array}{l}50^{\circ} \mathrm{C}, \\
350 \text { bar }\end{array}$ & $\begin{array}{l}60^{\circ} \mathrm{C}, \\
190 \text { bar }\end{array}$ & $\begin{array}{l}60^{\circ} \mathrm{C}, \\
270 \text { bar }\end{array}$ & $\begin{array}{l}60^{\circ} \mathrm{C}, \\
420 \text { bar }\end{array}$ & $\begin{array}{l}70^{\circ} \mathrm{C}, \\
220 \text { bar }\end{array}$ & $\begin{array}{l}70^{\circ} \mathrm{C}, \\
320 \text { bar }\end{array}$ & $\begin{array}{l}70^{\circ} \mathrm{C}, \\
490 \text { bar }\end{array}$ \\
\hline C8:0 & 0.6908 & 1.2668 & 0.8370 & 0.7730 & 1.5816 & 0.4008 & 0.3378 & 2.2799 & 0.0214 \\
\hline C10:0 & --------- & .0373 & 0299 & .0250 & 0415 & .0347 & ----- & --------- & $\begin{array}{l}----- \\
--1\end{array}$ \\
\hline C12:0 & 0.0759 & 0.1752 & 0.1735 & 0.1357 & .1925 & 0.2527 & 0.0767 & 0.3387 & 0.1414 \\
\hline C13:0 & --------- & --------- & --------- & -------- & $\begin{array}{ll}------ \\
\end{array}$ & $\begin{array}{ll}------- \\
\end{array}$ & 0.0234 & 0.2152 & \\
\hline C14:0 & 0.1332 & 0.2400 & 0.1695 & 0.1919 & 0.2120 & 0.3097 & 0.1358 & 0.4284 & 0.1882 \\
\hline $\mathrm{C} 15: 0$ & \begin{tabular}{|l|l}
-------- \\
\end{tabular} & --------- & --------- & --------- & ---- & --------- & $\begin{array}{l}-------- \\
\end{array}$ & --------- & $\begin{array}{l}-------- \\
\end{array}$ \\
\hline C16:0 & 28.1504 & 30.9182 & 23.4724 & 26.2933 & 29.2083 & 28.5832 & 25.4190 & 90.8646 & 27.8123 \\
\hline C16:1 & 4.9504 & 0.0304 & 5.4979 & 6.1487 & 7.0855 & 6.8369 & 4.1602 & 0.0850 & 5.8132 \\
\hline C17:0 & |-------- & 0.0423 & 0.1409 & 0.0320 & --------- & -------- & 0.0527 & 0.1905 & 0.0376 \\
\hline C18:0 & 1,0512 & 2554 & 1.0214 & 0.8039 & .1411 & 1.1647 & 1.4390 & 5.3583 & 1.3353 \\
\hline C18:1 & 64.8672 & 65.8103 & 52.7321 & 50.7890 & 60.4291 & 62.4172 & 55.7127 & 0.2394 & 64.6504 \\
\hline C18:2 & \begin{tabular}{|l|}
-------- \\
\end{tabular} & |-------- & 15.5448 & 14.8073 & --------- & (-------- & 12.5961 & --- & -- \\
\hline C18:3 & ----- & |-------- & --- & --------- & $--\cdot$ & --- & --------- & -- & -- \\
\hline C20:0 & 0.0810 & |-------- & --------- & --------- & 0.1087 & --------- & --------- & --------- & --------- \\
\hline C22:0 & |--------- & 0.2240 & 0.3807 & --------- & --------- & --------- & 0.0465 & --------- & --------- \\
\hline SFA & 30.1825 & 34.1592 & 26.2253 & 28.2548 & 32.4857 & 30.7458 & 27.5309 & 99.6756 & 29.5362 \\
\hline MUFA & 69.8176 & 65.8407 & 58.2300 & 56.9377 & 67.5146 & 69.2541 & 59.8729 & 0.3244 & 70.4636 \\
\hline PUFA & \begin{tabular}{|l|}
-------- \\
\end{tabular} & |-------- & 15.5448 & 14.8073 & --------- & (-------- & 12.5961 & (-------- & -------- \\
\hline
\end{tabular}

C8:0 (ácido caprílico); C10:0 (ácido capríco); C12:0 (ácido láurico); C13:0 (ácido tridecanoíco); C14:0 (ácido míristico); C15:0 (ácido pentadecanoíco); C16:0 (ácido palmítico); C16:1 (ácido 
palmitoleíco); C17:0 (ácido margárico); C18:0 (ácido esteárico); C18:1 ( ácido oleico); C18:2 ( ácido linoleico); C18:3 (ácido linolênico); C20:0 (ácido arachidico); C22:0 (ácido behênico);SFA (Ácidos Graxos Saturados); MUFA (Ácidos Graxos Monoinsaturados); PUFA (Ácidos Graxos Poliinsaturados).

\section{CONCLUSÕES}

O método de extração com dióxido de carbono no estado supercrítico foi eficaz na obtenção de extrato de açaí liofilizado principalmente na condição operacional de $70{ }^{\circ} \mathrm{C}$ e pressão de 490 bar onde obteve-se maior rendimento em extrato. Em todas as condições experimentais utilizadas neste trabalho, mostraram resultados promissores na obtenção de ácido graxos saturados e insaturados principalmente na obtenção de ácidos graxos monoinsaturados, onde a concentração destes ácidos no extrato foi de $70.46 \%$. A presença de ácidos graxos poliinsaturados representado pelo ácido oleico (C18:1), ácido palmitoleico (C16:1) e ácido linoleico (C18:2) foi significante no extrato.

\section{REFERÊNCIAS}

BHATTACHARJEE, P.; SINGHAL, R. S.; TIWARI, S. R. Supercritical carbon dioxide extraction of cottonseed oil. Journal Food Engineering., v. 79, n.3, p. 892-898, 2007.

BOtelHO, J. R. S.; MEDEIROS, N. G.; RODRIGUES, A. M. C.; ARAÚJO, M. E.;MACHADO, N. T.; SANTOS, A. G.; LEAL, G. W.; CARVALHO JR, R. N. Black sesame (Sesamumindicum $l$ ) seeds extracts by $\mathrm{CO}_{2}$ supercritical fluid extraction: Isotherms of global yield, kinetics data, total fatty acids, phytosterols and neuroprotective effects. Journal of Supercritical Fluids, 2014.

GARCÍA-RISCO, M. R.; VICENTE, G.; REGLERO, G.; FORNARI, T. Fractionation of thyme (Thymus vulgaris L.) by supercritical fluid extraction and chromatography. Journal of Supercritical Fluids. v. 55, p. 949-954, 2011.

NASCIMENTO, R. J. S. do; COURI, S.; ANTONIASSI, R.; FREITAS, S. P. Composição em ácidos graxos do óleo da polpa de açaí extraído com enzimas e com hexano. Revista Brasileira de Fruticultura, v.30, n.2, p. 498-502, 2008.

RODRIGUES, A.M.C; DARNET, S.H; SILVA, L.H. Fatty acid profiles and tocoferol contentes of buriti (Mauritia flexuosa), patawa (Oenocarpus bataua), tucumã (Astrocaryum vulgare), mari (Poraqueiba paraensis) and inaja (Maximiliana maripa) fruits. Journal of Brazilian Chemical Society. Vol. 21, 2010. p. 2000-2004

ROGEZ, H. Açaí: Preparo, Composição e Melhoramento da Conservação. Belém: EDUFPA, 2000. 313p

SCHAUSS, G. A.; WU, X.; PIOR, R. L.; OU, B.; PATEL, D.; HUANG, D.; KABABICK, J. P. Phytochemical and Nutrient Composition of the Freeze-Dried Amazonian Palm Berry, 
Euterpe oleraceae Martius (Acai). Journal of Agriculture and Food Chemistry, v. 54, n.22, p. 8598-8603, 2006.

SILVA, F. P. T.; LIBERAL, E. M.; PESSOA, F. L. P. Uso do fluido supercrítico na extração de produtos naturais. Boletim da Sociedade Brasileira de Ciência e Tecnologia de AlimentosSBCTA. v.31, p.48-61, jan/jun, 1997.

WENNERSTEN, R. Extraction of organic compounds. Chap 9. In: RYDBERG, J.; MUSIKAS, C.; CHOPPIN, G. R. Principles and practices of solvent extraction. New York: Marcel Dekker, p. 115-356, 1992. 